UCRL-JC-110714

PREPRINT

\title{
Design of Pulse Stretching Cell for a Sodium Guide Star Optical System
}

\author{
Herbert W. Friedman, James A. Horton, \\ Thomas J. Kuklo and Nan J. Wong
}

This paper was prepared for submittal to OPTCON ' 92 Conference held in Boston, Massachusetts

November 17-21, 1992

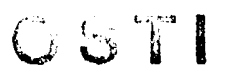

November 10, 1992

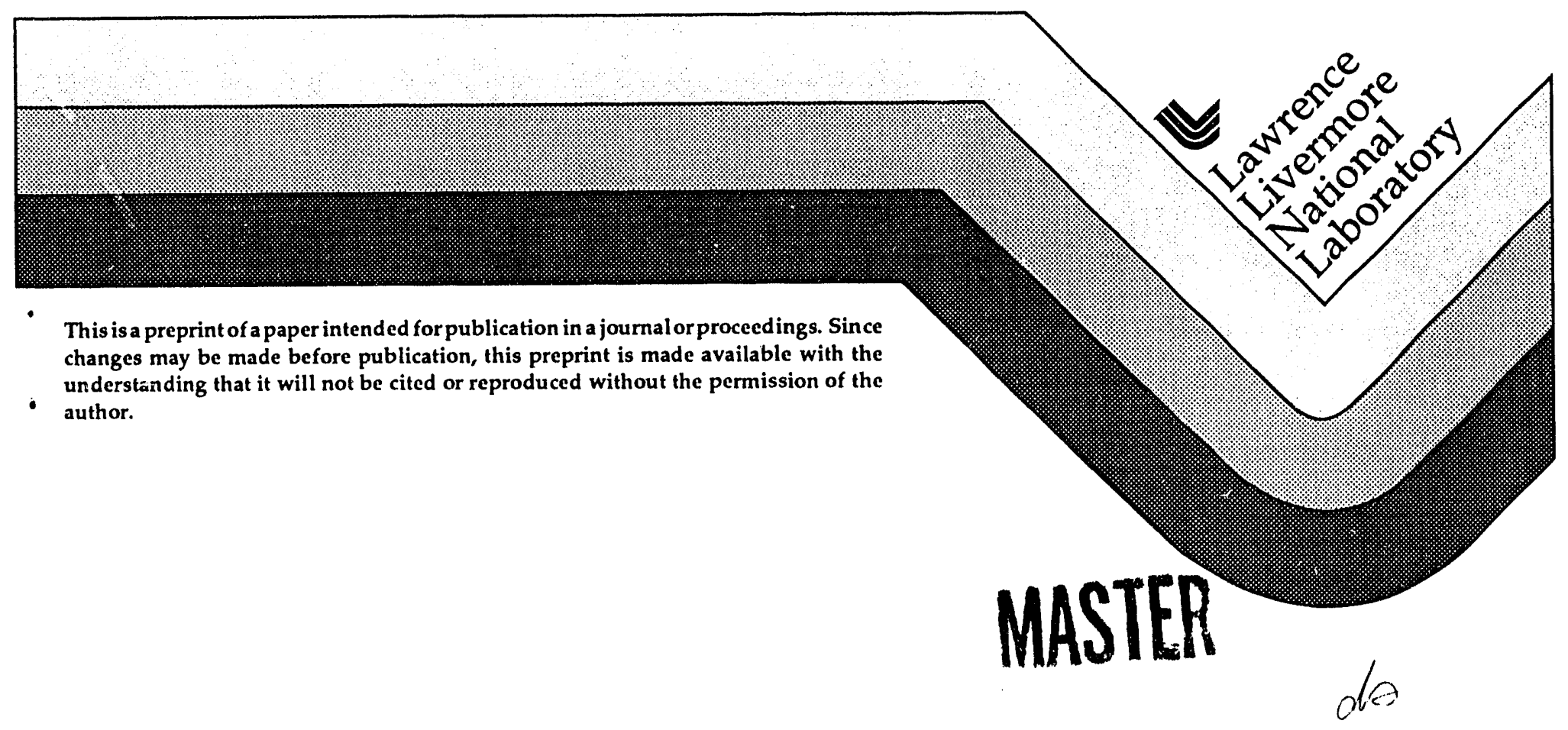

BISTRIBUTION OF THIS DOCUMENT IS URLIMITEN 


\section{DISCLAIMER}

This document was prepared as an account of work sponsored by an agency of the United States Government. Neither the United States Government nor the University of California nor any of their employees, makes any warranty, express or implied, or assumes any legal liability or responsibility for the accuracy, completeness, or usefulness of any information, apparatus, product, or process disclosed, or represents that its use would not infringe privately owned rights. Reference herein to any specific commercial products, process, or service by trade name, trademark, manufacturer, or otherwise, does not necessarily constitute or imply its endorsement, recommendation, or favoring by the United States Government or the University of California. The views and opinions of authors expressed herein do not necessarily state or reflect those of the United States Government or the University of California, and shall not be used for advertising or product endorsement purposes. 


\title{
Design of Pulse Stretching Cell for a Sodium Guide Star Optical System*
}

\author{
Herbert W. Friedman, James A. Horton, Thomas C. Kuklo, Nan J. Wong \\ Lawrence Livermore National Laboratory \\ Box 808 \\ Livermore, CA 94550 \\ (510)-422-2257
}

A pulse stretcher has been designed for the LLNL sodium guide star experiment to lower the laser flux and avoid saturation effects. The optical design, mechanical layout and wavefront error analysis is presented.

*This work was performed under the auspices of the U. S. Department of Energy by Lawrence Livermore National Laboratory under contract No. W-7405-ENG-48. 


\title{
Design of Pulse Stretching Cell for a Sodium Guide Star Optical System*
}

\author{
Herbert W. Friedman, James A. Horton, Thomas C. Kuklo, Nan J. Wong \\ Lawrence Livermore National Laboratory
}

LLNL has planned a demonstration experiment of an adaptive optics system to correct large astronomical telescopes for the effects of atmospheric turbulence. The optical system features a guide star created in the mesospheric sodium layer at $90 \mathrm{~km}$ using a high power dye laser system developed at LLNL for the Atomic Vapor Laser Isotope Separation (AVLIS) program. This laser system has an average power of $1.5 \mathrm{~kW}$, pulse repetition frequency of $26 \mathrm{kHz}$, and a pulse duration of approximately $40 \mathrm{~ns}$ (FWHM). With these parameters, the peak laser flux at the sodium layer is approximately $75 \mathrm{w} / \mathrm{cm}^{2}$ assuming a spot diameter of $1.5 \mathrm{~m}$. This spot diameter corresponds to the resolution limit of a sub aperture whose diameter is equal to the atmospheric seeing parameter, $\mathrm{r}_{0}$, which at LLNL is about $5 \mathrm{~cm}$ (in the visible). Creation of the guide star at the resolution limit of this sub aperture is crucial to the straightforward operation of the adaptive optics system.

A loss of back scatter efficiency arises with a laser flux of this magnitude because it exceeds the saturation flux ${ }^{1}$ of the sodium atoms and stimulates the reradiated light in the forward direction away from the wave front sensor located at the telescope. A higher percentage of the incident flux is reradiated back to the ground if the incident flux can be lowered below the saturation level which is approximately $5 \mathrm{w} / \mathrm{cm}^{2}$. The reduced incident peak flux is to be maintained at constant average power and constant PRF, hence, the pulse duration must be extended.

An optical system which stretches the $40 \mathrm{~ns}$ pulse by the required factor of 15 has been designed. A schematic representation of the concept is shown in the figure. The pulse stretcher uses a beam splitter/mirror combination and four delay cells to achieve the desired result. The output of the system is a double stream of pulses identical to the input pulse but each reduced in amplitude by a factor of $1 / 15$ and arranged "head-to-tail" to form the stretched pulse format. The two streams can be combined using a polarization rotator/combiner or left in two parallel streams. For propagation to the sodium layer, a single beam train is not required and two parallel beam trains are acceptable.

The individual delay cells provide delays of 1,2,4 and 8 times the input pulse length and are arranged in a three mirror, confocal White ${ }^{2}$ cell configuration. The confocal cells provide an imaging capability so that the effects of diffraction in these long propagation paths are eliminated and all that remains is the diffraction caused by the small path lengths of the beam splitter paths. High mirror reflectivity and low absorption in the coatings are essential for efficient operation of this multipass system. The coatings developed for the AVLIS program provide $R \geq 0.998$ and absorption of the order of a few parts in $10^{5}$ which results in a transmission for the system of greater than $85 \%$ and low thermal induced errors. Low absorption coatings are essential in this application since the pulse stretcher operates at the full power of the beam, i.e., at kilowatt levels. A detailed wavefront analysis including geometric, surface and thermal induced wavefront errors has been completed with the total wavefront error estimated at $1 / 20$ wave (RMS). 
The present opto-mechanical design for the pulse stretcher uses four separate White cells and discrete beam splitter elements to allow maximum flexibility. A key technical issue is the degree of control necessary to maintain beam centering and pointing accuracy at the kilowatt level. Prepackaged, closed loop beam control systems developed for the AVLIS program will be used to maintain alignment but a near term goal of the project will be to investigate temporal and/or spatial sharing techniques to reduce the number of such control loops. The present design will be housed in a long, wall mounted vacuum chamber with large doors to permit maximum flexibility. A preliminary design for a compact version has also been completed and fits in a vacuum pipe of 18 inch diameter and 15 feet length.

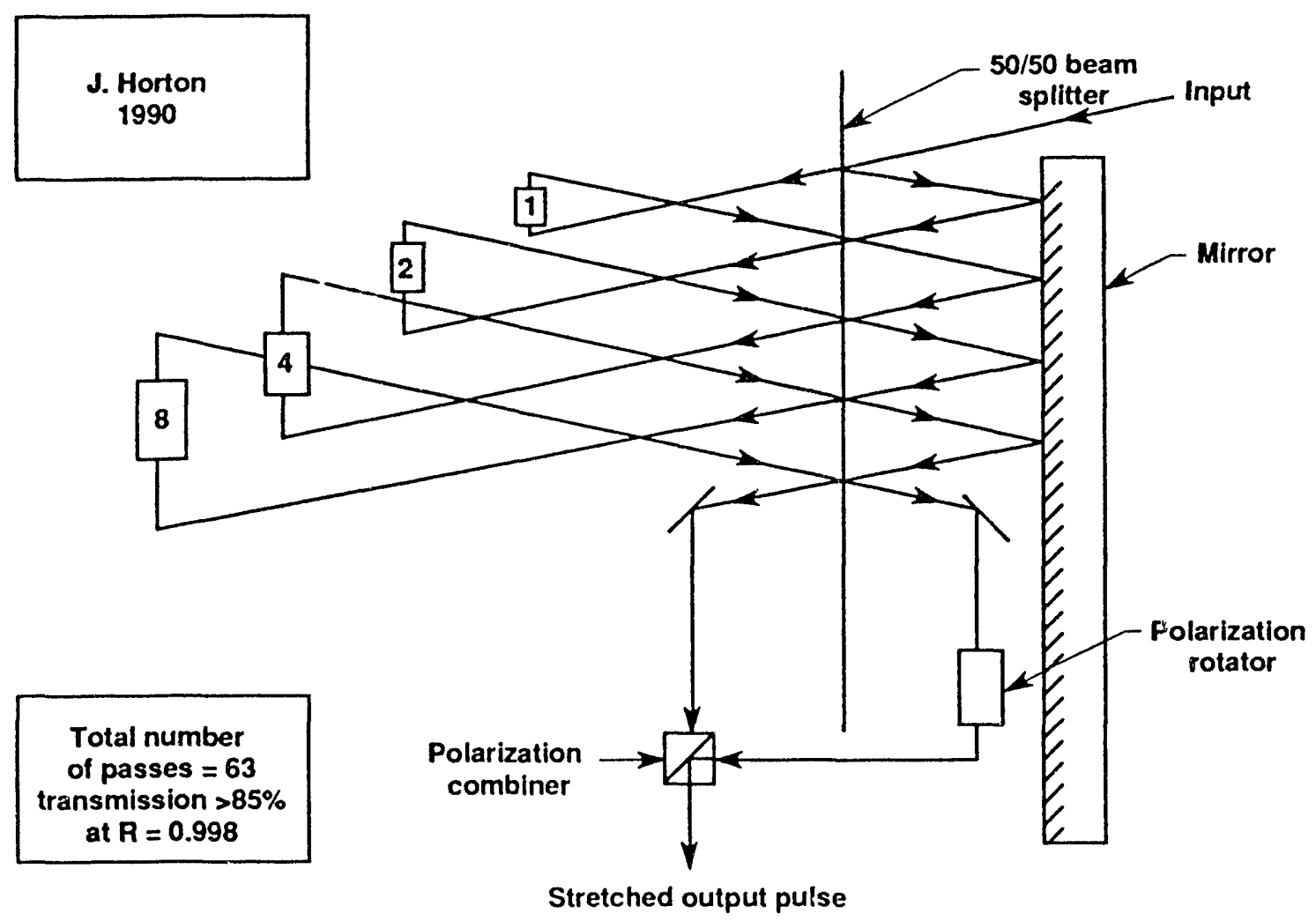

Pulse stretcher optical design.

\section{References:}

1. C. S. Gardner, B. M. Welsh and L. A. Thompson, Proc. IEEE, 78, 11, (1990), p. 1721.

2. J. U. White, JOSA, 32, (1942), p.285.

*This work was performed under the auspices of the U. S. Department of Energy by Lawrence Livermore National Laboratory under contract No. W-7405-ENG-48. 

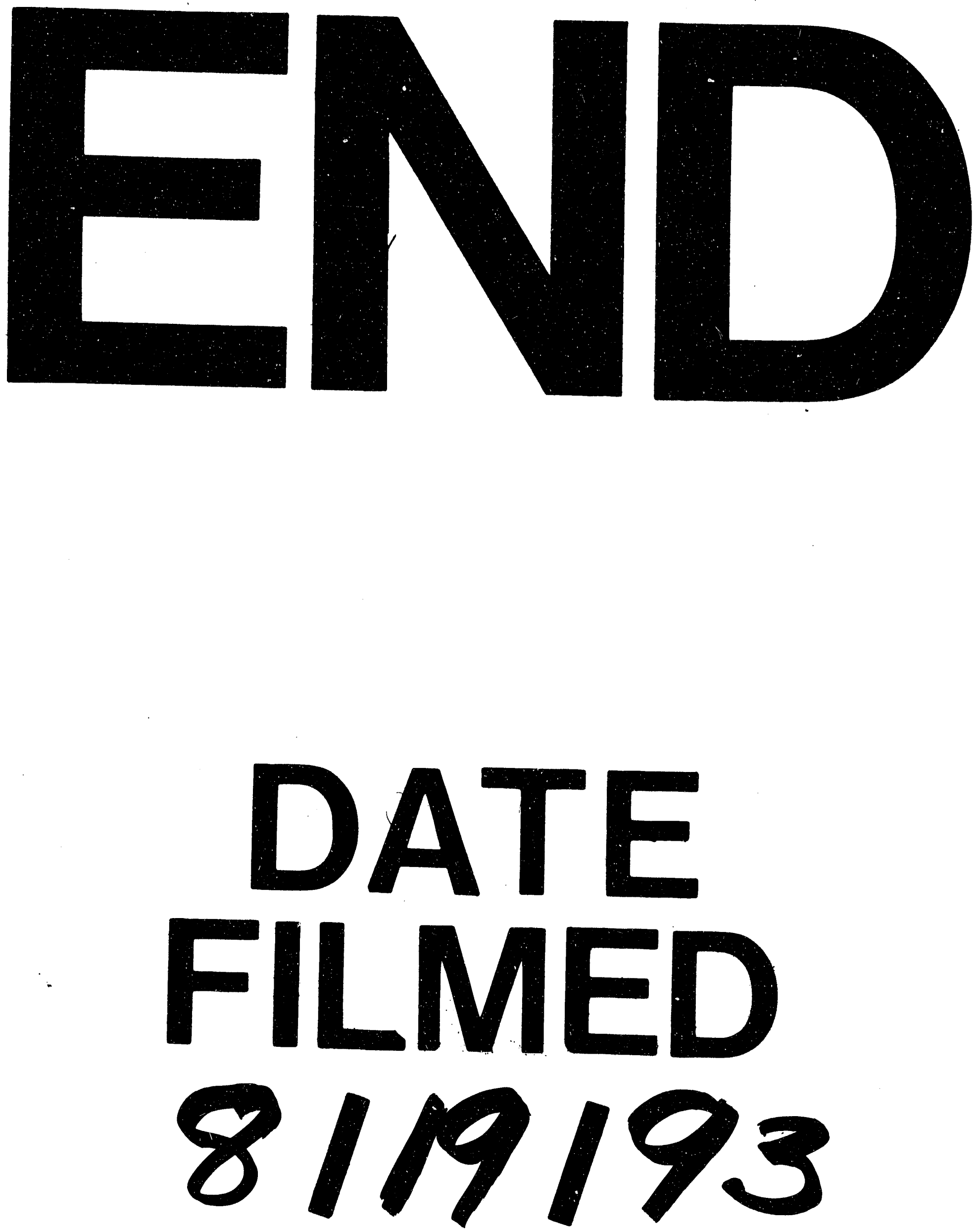
